
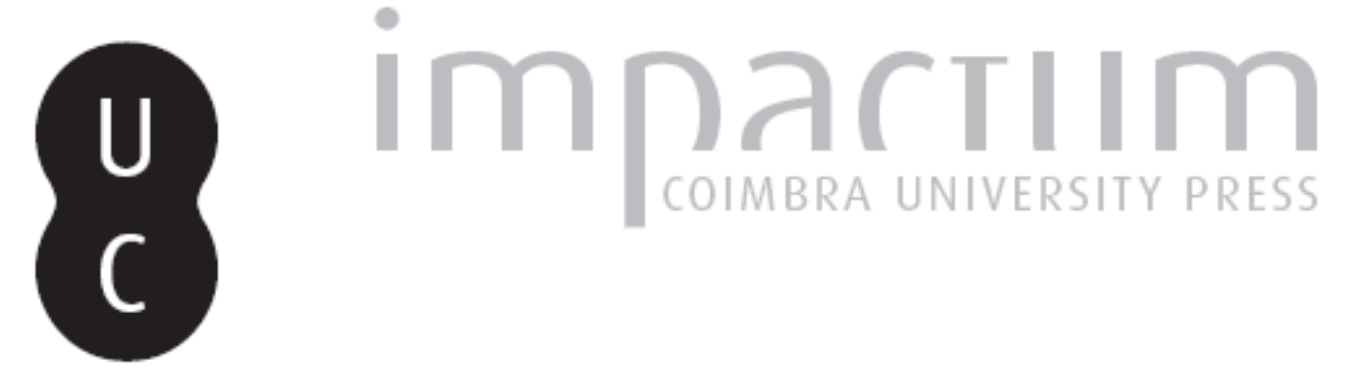

\title{
A imagem cinematográfica em João César Monteiro: recordações da casa amarela, crítica, abstracção e empatia
}

Autor(es): $\quad$ Nogueira, Isabel

Publicado por: Imprensa da Universidade de Coimbra

URL persistente:

URI:http://hdl.handle.net/10316.2/36443

DOI:

DOI:http://dx.doi.org/10.14195/1647-8622_10_12

Accessed : $\quad$ 26-Apr-2023 15:42:05

A navegação consulta e descarregamento dos títulos inseridos nas Bibliotecas Digitais UC Digitalis, UC Pombalina e UC Impactum, pressupõem a aceitação plena e sem reservas dos Termos e Condições de Uso destas Bibliotecas Digitais, disponíveis em https://digitalis.uc.pt/pt-pt/termos.

Conforme exposto nos referidos Termos e Condições de Uso, o descarregamento de títulos de acesso restrito requer uma licença válida de autorização devendo o utilizador aceder ao(s) documento(s) a partir de um endereço de IP da instituição detentora da supramencionada licença.

Ao utilizador é apenas permitido o descarregamento para uso pessoal, pelo que o emprego do(s) título(s) descarregado(s) para outro fim, designadamente comercial, carece de autorização do respetivo autor ou editor da obra.

Na medida em que todas as obras da UC Digitalis se encontram protegidas pelo Código do Direito de Autor e Direitos Conexos e demais legislação aplicável, toda a cópia, parcial ou total, deste documento, nos casos em que é legalmente admitida, deverá conter ou fazer-se acompanhar por este aviso.

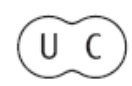




\section{crises do século}

\section{ESTUD OSD OSÉCULO}

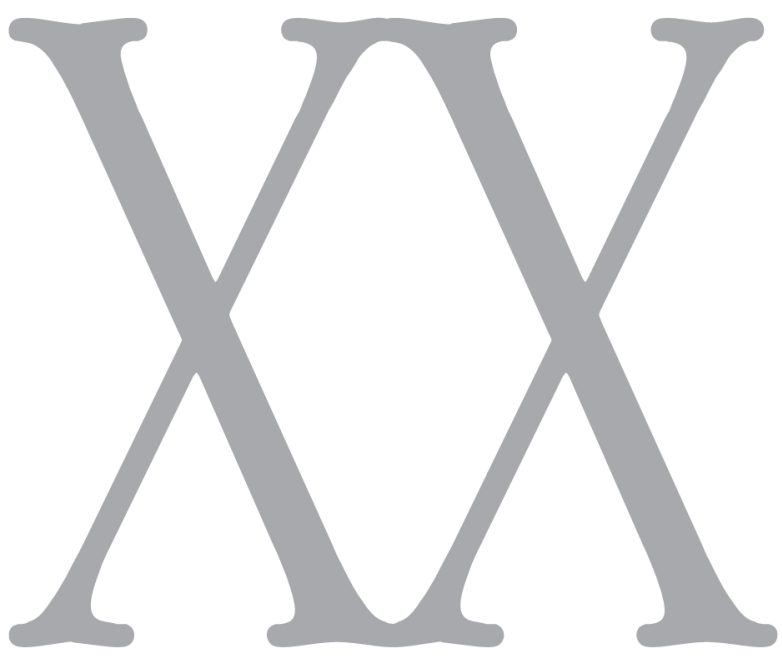

número $10 \cdot 2010$

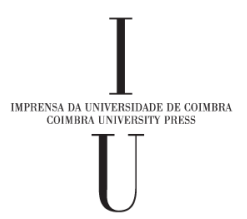




\section{A imagem cinematográfica em Joáo César Monteiro}

Recordaçôes da casa amarela, crítica, abstracção e empatia

Isabel Nogueira 
Isabel Nogueira, doutorada em Belas-Artes, área de especialização em Ciências da Arte, pela Faculdade de Belas-Artes da Universidade de Lisboa, bolseira de pós-doutoramento da FCT, Investigadora do CEIS20. E-mail: isabelmnogueira@hotmail.com. 
A imagem na obra de João César Monteiro (1939-2003) é poderosa e reveste-se de contornos complexos. Na verdade, como o próprio afirmou: «(...) a beleza do mundo, como se sabe, é a beleza do cinema» ${ }^{1}$. Mas como fixar e revelar esta beleza? Um modo possível de trabalhar esta questão prende-se com a dicotomia abstracçáo-empatia, tema da dissertação de Wilhelm Worringer (1881-1965), apresentada na Alemanha, em $1907^{2}$. Esta tese, na opinião de Udo Kultermann, "teve consequências como poucas teses doutorais em história da arte tiveram» ${ }^{3}$.

Worringer, partindo de ideias já avançadas por Aloïs Riegel - abstracção como resultante da kustwollen, isto é, da "vontade artística» do momento - e por Theodor Lipps - incremento do conceito de einfühlung, genericamente traduzido por "empatia» ou por "gozo objectivado em si" - identificou as duas principais directrizes da arte. Por um lado, a abstracção, que acreditou desempenhar um papel preponderante na história da arte, ao relacioná-la com uma cultura primitiva colectiva, pura e plena de referências. Por outro, a empatia, enquanto o modo realista, individual e orgânico de operar desde o Renascimento. Tal como sintetiza Jacques Aumont, a abstracção funcionaria como uma compensação face à angústia do mundo; o realismo/naturalismo como identificação empática com o mundó . De facto, o impulso de satisfação encontraria eco na beleza do orgânico, isto é, do finito, demonstrável, redondo. Por seu lado, o impulso abstracto encontra a sua operacionalidade na beleza inorgânica, não finita, regida por leis e dinâmicas do domínio da abstracção. A necessidade de abstracção prende-se justamente com a fragilidade das estruturas objectivas de compreensão do mundo; com a motivação profunda em revelar aspectos que ultrapassam a superficialidade do imediatamente visível, da aparência reconhecível e reproduzível, por outras palavras, mimética.

Os trabalhos de Wilhelm Worringer foram contributos relevantes para a afirmação do expressionismo, surgido na Alemanha e primeiramente ligado às artes plásticas, não obstante a denominação ter sido inicialmente aplicada a um grupo de pintores franceses associados a Henri Matisse e, só em 1914, ter sido usada pelo crítico Paul Fechter para se referir a artistas alemães, na obra Der expressionismus. $\mathrm{Na}$ senda da abstracção, e do ponto de vista visual, este movimento pautou-se basicamente pelo uso da deformação anatómica na representação expressiva. Devemos, no entanto, notar que esta característica existiu em variadas formas de arte - no gótico ou no maneirismo, por exemplo - mas o vocábulo aplicado especificamente a um movimento estético foi apanágio do século XX. Por outro lado, o expressionismo foi o primeiro movimento a alcançar os terrenos da pintura, da escultura, da arquitectura, da música, do teatro, da literatura e do cinema.

O expressionismo reivindicava a liberdade criativa e expressiva, contra o conservadorismo e o academismo. Estas premissas assinalavam o ponto de partida do expressionismo alemão, no qual se destacaram, nas artes plásticas, Ernst Ludwig

\footnotetext{
${ }^{1}$ MONTEIRO, João César - Les sanglots longs des violons de l'automne... Trafic. N. ${ }^{\circ} 50$ (Verão 2004) p. 92.

${ }^{2}$ Ver WORRINGER, Wilhelm - Abstraction et einfühlung. Paris: Klincksieck, 1978.

${ }^{3}$ KULTERMANN, Udo - Historia de la historia del arte: el caminho de una ciencia. Madrid: Ediciones Akal, 1996, p. 274.

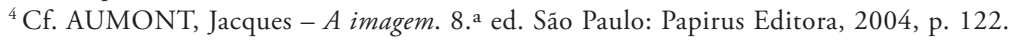


Kirchner, Erich Heckel, Fritz Bleyl, Karl Schmidt-Rottluff, Alexey Von Jawlensky, August Macke, Franz Marc, Marianne Werefkin, Wassily Kandinsky, entre outros. Unia estes artistas a forte convicção de que a obra de arte já não podia existir como representante da realidade, pelo menos de maneira ilusória e superficial. Segundo Alfredo Aracil: "A introspecção psicológica das personagens, a indiferença face ao ideal clássico de "beleza», a dureza da linha ou a distorção do colorido e o desenho serão considerados, mais do que uma tendência, a consequência de uma concepção global da arte como expressão emocional» ${ }^{5}$. A carga pessimista, a figura humana profundamente solitária, a representação dos «instintos bárbaros» — o grito, o riso, a sexualidade — afastavam definitivamente o expressionismo do fauvismo, o seu movimento antecessor.

$\mathrm{Na}$ obra Ueber das geistige in der kunst, insbesondere in der malerei (Do espiritual na arte, escrita em 1910 e editada em 1911) Kandinsky esboçou a estética da arte abstracta, começando precisamente por afirmar:

Tentar ressuscitar os princípios da arte dos séculos passados só pode conduzir à produção de obras abortadas. Assim como é impossível fazer reviver em nós o espírito e as formas de sentir dos antigos Gregos, todos os esforços tentados no sentido de aplicar os seus princípios - por exemplo, no domínio da plástica - apenas levarão ao aparecimento de formas semelhantes às gregas. A obra assim produzida jamais possuirá uma alma. Esta imitaçáo assemelha-se à dos macacos ${ }^{6}$.

Trata-se, efectivamente, do emergir de uma forma nova - inserida no movimento mais vasto do modernismo e da categoria crítica da vanguarda - de entender o mundo e de o representar. Segundo Pierre Francastel (1954): "O que aparece no início do século XX não é (...) o problema - negativo - da deslocação dos planos, das formas e dos objectos tradicionais; é o da constituiçáo de um novo sistema de representação, positiva e integral, dos fenómenos sensíveis»?

No domínio do cinema o expressionismo assume a plástica por excelência. $\mathrm{Na}$ perspectiva de Jacques Aumont: "O expressionismo alemão seria o lugar privilegiado de um encontro perfeito e quase uma fusão entre a pintura - no seu estado mais pictórico - e o cinema» ${ }^{8}$. Esta síntese aparece claramente expressa na deformação, intensificação e estilização simbólica da imagem, bem como nos contrastes carregados e plenos de dramatismo. O expressionismo alemão, embora em sentido estrito agrupe um número não muito elevado de filmes - de que são exemplos Das Kabinett des Dr. Caligari (Robert Wienne, 1919), Dr. Mabuse (Fritz Lang, 1922), Nosferatu, eine symphonie des grauens (F. W. Murnau, 1922), Schateen (Robinson, 1923), ou Die Nibelungen (Fritz Lang, 1923-1925) - constituiu uma escola importante, que se desenvolve na Berlim do contexto do pós-guerra. Interessa-nos particularmente Nosferatu, eine symphonie des grauens, justamente porque também interessou a João

5 ARACIL, Alfredo; RODRÍGUEZ, Delfín - El siglo XX. Entre la muerte del arte y el arte moderno. Madrid: Ediciones ISTMO, 1998, p. 83.

${ }^{6}$ KANDINSKY, Wassily - Do espiritual na arte. 6. ${ }^{\mathrm{a}}$ ed. Lisboa: Publicaçóes Dom Quixote, 2003, p. 21.

${ }^{7}$ FRANCASTEL, Pierre - A imagem, a visão e a imaginação: objecto fílmico e objecto plástico. Lisboa: Ediçōes 70, 1998, p. 221.

${ }^{8}$ AUMONT, Jacques - El ojo interminable: cine y pintura. Barcelona: Paidós, 1997, p. 148. 
César Monteiro: "O génio de Murnau é este segredo incomparável de através das formas do corpo descobrir o conteúdo da alma, através das aparências nos revelar o ser, através do falso nos transmitir o verdadeiro. Um olhar que mergulhando no real nos manifesta subitamente a presença do fantástico». ${ }^{9}$. E estamos justamente perante as ideias de "abstracção" e "empatia" de Worringer.

A referência a Nosferatu é particularmente visível em Recordaçóes da casa amarela: uma comédia lusitana (cor, 35mm, 120', Leão de Prata - Festival de Veneza), com direcção de fotografia de José António Loureiro, primeiro filme de uma notável trilogia - A comédia de Deus (1995) e As bodas de Deus (1998) -, a "trilogia de Deus» ${ }^{10}$. A personagem interpretada por si próprio - João de Deus - consegue assemelhar-se, sem caracterização aparente, ao esguio e desajeitado vampiro de Murnau. No desfecho de Recordaçôes da casa amarela, João de Deus - indivíduo de meia-idade, errante, "pó enamorado», «intelectual de esquerda», solitário e fisicamente debilitado -, depois de ter sido dado como louco e de ter reencontrado num hospício Lívio - personagem de Quem espera por sapatos de defunto morre descalço, 1970, novamente interpretada por Luís Miguel Cintra -, emerge de um alçapáo fumegante, num beco tipicamente lisboeta - basta, de resto, reparar nos painéis de azulejo azul e branco, à maneira barroca, na parede que lhe serve de cenário -, afugentando as crianças que levantam a tampa do "Inferno». Estamos perante uma situação de simbiose entre a abstracção e a empatia, o purismo essencial e o realismo mundano, ou o recôndito e o visível.

É, de facto, este plano-sequência final, catártico e expiatório, que Murnau e César Monteiro mais clara e assumidamente se fundem. Mas também os conceitos de arte de Worringer. Recordaçôes da casa amarela é um filme com sucessivos mise en abyme - dialogais e imagéticos -, com pequenas narrativas dentro da narrativa principal, cujo enquadramento nos reporta para a transtextualidade dialógica, bem como para a relação semiológica entre significante e significado. Vejamos alguns exemplos desta relação worringeriana entre a abstracção expressionista citada de Nosferatu e o realismo vernacular português.

À semelhança do que maioritariamente sucede em Nosferatu, o filme de César Monteiro é gravado em cenários naturais, realistas, reconhecíveis pelo espectador, tais como ruas, edifícios, mobiliário, figurinos, etc. Desde logo, o primeiro plano-sequência do filme mostra-nos, com Lisboa por fundo, uma embarcação que recorda a caravela portuguesa, navio semelhante ao que também aparece no filme de Murnau e que transporta o vampiro. A própria figura sinistra, mais ou menos caricatural, da viúva portuguesa - Dona Violeta (Manuela de Freitas), a dona da pensão - podia perfeitamente habitar os filmes do realizador alemáo, especialmente quando a sua silhueta negra surge dramaticamente ressaltada por uma parede branca.

Estas associaçôes "abstractas-empáticas» vão pontuando Recordaçóes da casa amarela, por exemplo, através da imagem que coloca João de Deus - vampiro que está prestes a «sugar» o salário da máe - lado a lado com uma escultura de um anjo barroco, ou da sua paixão predadora pela donzela, ou ainda dos dramáticos jogos de espelhos - no

\footnotetext{
${ }^{9}$ MONTEIRO, João César - Sunrise. O Tempo e o Modo. N. 27 (Maio 1965) p. 562.

${ }^{10}$ Cf. COSTA, João Bénard da - «César Monteiro: depois de Deus». In João César Monteiro. Lisboa: Cinemateca Portuguesa - Museu do Cinema, 2005, p. 381-403.
} 
restaurante, na leitaria do bairro, na casa de alterne, no quarto de Mimi, no quarto da Menina Julieta, ou na barbearia -, das deambulaçóes de Joấo de Deus pelas ruas e becos de Lisboa filmados em plongée e contre-plongée, ou mesmo das janelas com reposteiros de tecido damasco - tão caras ao cinema expressionista como a Eça de Queiroz.

Em Recordaçôes da casa amarela, João César Monteiro consegue, de facto, construir uma imagética capaz de reunir em si referências históricas e estéticas do cinema clássico ocidental, concretamente do cinema de Murnau, e âncoras do imaginário e do modo de viver portugueses, numa particular simbiose da compensaçáo com o gozo objectivado em si, constituindo uma forma crítica de compreensão do país e do próprio cinema, enquanto modo de ver o mundo, portanto, mediação desse mesmo mundo.

\section{REFERÊNCIAS BIBLIOGRÁFICAS}

ALMEIDA, Bernardo Pinto de - O plano de imagem: espaço da representaçâo e lugar do espectador. Lisboa: Assírio \& Alvim, 1996.

ARACIL, Alfredo; RODRÍGUEZ, Delfín - El siglo XX. Entre la muerte del arte y el arte moderno. Madrid: Ediciones ISTMO, 1998.

ARENAS, José Fernández - Teoría y metodología de la historia del arte. 2. a ed. Barcelona: Anthropos Editorial del Hombre, 1984.

AUMONT, Jacques - $A$ imagem. 8. a ed. São Paulo: Papirus Editora, 2004.

- El ojo interminable: cine y pintura. Barcelona: Paidós, 1997.

BAYER, Raymond - História da estética. Lisboa: Editorial Estampa, 1995.

BEHR, Shulamith - Expressionismo. Lisboa: Editorial Presença, 2000.

BONFAND, Alain - L'art abstrait. 2e éd. Paris: Presses Universitaires de France, 1995.

CHALUMEAU, Jean-Luc - As teorias da arte: filosofia, critica e história da arte de Platão aos nossos dias. Lisboa: Instituto Piaget, 1997.

COSTA, João Bénard da - «César Monteiro: depois de Deus». In João César Monteiro. Lisboa: Cinemateca Portuguesa - Museu do Cinema, 2005. p. 381-403.

DUBE, Wolf-Dieter - The expressionists. New York: Thames \& Hudson, 2001.

FRANCASTEL, Pierre - A imagem, a visão e a imaginação: objecto fílmico e objecto plástico. Lisboa: Ediçôes 70, 1998.

GRILO, João Mário (introd.); BAPTISTA, Tiago (ed.) - Os filmes da nossa casa: Ciclo de Cinema na Faculdade de Ciências Sociais e Humanas da Universidade Nova de Lisboa. Lisboa: Mediateca da FCSH, 2008.

HAUSER, Arnold - Teorias da arte. 2.a ed. Lisboa: Editorial Presença, 1988.

HUESO, Angel Luis - El cine y el siglo XX. Barcelona: Editorial Ariel, 1998.

KANDINSKY, Wassily - Do espiritual na arte. 6. ${ }^{a}$ ed. Lisboa: Publicaçóes Dom Quixote, 2003.

KULTERMANN, Udo - Historia de la historia del arte: el caminho de una ciencia. Madrid: Ediciones Akal, 1996.

MACHADO, Paula; LEVY, Paula; SILVA, Jorge Pereira da; TRINDADE, António - João César Monteiro: cineasta: 1939-2003. Lisboa: Câmara Municipal-Comissão Municipal de Toponímia, 2007. 
MARTIN, Marcel - A linguagem cinematográfica. Lisboa: Dinalivro, 2005.

MICHELI, Mario de - As vanguardas artísticas do século XX. São Paulo: Martins Fontes, 1991.

MONTEIRO, João César - Les sanglots longs des violons de l'automne... Trafic. N. ${ }^{\circ} 50$ (Verão 2004) p. 89-92.

- Sunrise. O Tempo e o Modo. N.o 27 (Maio 1965) p. 561-562.

MUKAROVSKY, Jan - Escritos sobre estética e semiótica da arte. Lisboa: Editorial Estampa, 1993.

MURNAU. Lisboa: Cinemateca Portuguesa, 1989.

OSBORNE, Harold - Estética e teoria da arte. São Paulo: Editora Cultrix, 1968.

PERNIOLA, Mario - A estética do século XX. Lisboa: Editorial Estampa, 1998.

PINA, Luís de - História do cinema português. Lisboa: Publicaçôes Europa-América, 1986.

RAMOS, Jorge - Dicionário do cinema português: 1962-1988. Lisboa: Caminho, 1989.

READ, Herbert - A filosofia da arte moderna. Lisboa: Editora Ulisseia, [s.d.].

Recordaçôes da casa amarela [visual gráfico]: uma comédia lusitana de João César Monteiro. [Porto]: Invicta Filmes, 1989.

VIVEIROS, Paulo - A imagem do cinema: história, teoria e estética. Lisboa: Ediçóes Universitária Lusófona, 2002.

WORRINGER, Wilhelm - Abstraction et einfühlung. Paris: Klincksieck, 1978. 